\title{
Mobile Number Portability: A Case Study of Kenya
}

\author{
Metto S. Kimutai ${ }^{1}$, Kimeli V. Kimutai ${ }^{1}$, Awuor F. Mzee $^{2}$ \\ ${ }^{1}$ Department of Mathematics and Computer Science, University of Eldoret, Eldoret, Kenya \\ ${ }^{2}$ Department of Computing Sciences, Kisii University, Kisii, Kenya \\ Email: skmetto@yahoo.com,vkkimeli99@yahoo.com, fredrickawuor@gmail.com
}

Received September 25, 2013; revised October 25, 2013; accepted November 2, 2013

Copyright (C 2013 Metto S. Kimutai et al. This is an open access article distributed under the Creative Commons Attribution License, which permits unrestricted use, distribution, and reproduction in any medium, provided the original work is properly cited.

\begin{abstract}
In the telecommunications industry, mobile numbers are increasingly being seen as an asset of the regulator. The freedom of the customer using it is left to him/her to decide which service provider to use while retaining the same number. Mobile number portability (MNP) has been introduced to provide a platform for this freedom to the customer. The Telecommunications market Regulator in Kenya, the Communication Commission of Kenya (CCK), began the course of mobile number portability in 2010 through newspaper advertisement. The regulator had an aim that in the end, the right customer experience will be provided by the service providers, and help service providers to build profitable and lasting relationships between the service providers and their customer, and to differentiate themselves in the market. In this paper, we seek to evaluate the performance of MNP in Kenya since its launch. This paper seeks to find out how the service has performed after the first three months of operation. We survey and analyze MNP framework in Kenya and compare that to MNP in Japan, Finland, Sweden and Hong Kong to establish the future of MNP in Kenya. It first looks at the MNP framework as used in Kenya and the procedure for reversal in case the customer is dissatisfied with a service provider who moves to and makes a reference to how the service has performed in other markets such as Finland, Sweden, and Hong Kong in order to enable comparative observations. Since there has been very little literature published for countries in Africa, it will only make comments on countries like Egypt, South Africa and Nigeria. Further, it gives recommendations to the participating parties.
\end{abstract}

Keywords: Communication Commission of Kenya; Customer; Mobile Number Portability; Service Provider

\section{Introduction}

Mobile number portability (MNP) is the ability of a customer to change their mobile network operator and/or service provider while retaining the same mobile phone number for the provision of the same service as explained by Durukan et al. [1]. It is aimed at deregulating the telecommunications sector by reducing the former fixed association between the service providers and the mobile subscriber while promoting competition in the marketplace for mobile services. Mobile numbers are continually being seen as a property of the regulators and so the freedom is left to the subscriber on which service provider to use while retaining the same number.

Telecommunications market regulator, the Communication Commission of Kenya CCK initiated the process of mobile Number portability in 2010 through newspaper advertisements asking the public to submit their views on the need for number portability service. CCK assigned a third party-Mobile Porting Access Limited, the duty of rolling out the MNP in Kenya in April 2010.

This paper is organized as follows: Section 2 reviews the experiences in various countries; Section 3 presents the technical implementation of MNP, while Section 4 explains the findings and Section 5 deals with recommendations for adoption of newer technology in future. Conclusion and future work is presented in Section 6 .

\section{Literature Review}

Some of the issues mentioned to have caused the need for introduction of MNP center on network quality and calling rates. Specific issues mentioned include: Dropped calls, international calling rates, Static and unclear calls, over charging on calls claims, SMS adverts from specific mobile service providers (which often are broadcasted at night causing unnecessary attention), delays in delivery of services such as sms, failure to deliver services at all, low quality of network value added services such as launching of $3 \mathrm{G}$ services, higher calling rates, offers 
from various competitors and the fear of losing the number which made providers with a large customer base tending to provide less quality of services and exploitation of customers while customers have little or no options. Several options have been tried by customers including having multiple subscriber Identity Modules (SIM) cards, buying dual-sim phones or even carrying multiple handsets each with a different number from a different mobile service provider.

In the search for provision of a solution to these problems, Mobile Porting Access was licensed by the regulator CCK to enable customers to make a choice of a provider and retain the number he/she is identified with. Benchmark studies carried out by CCK indicates that Service Provider Number Portability (SPNP) offers effective intervention in markets that are dominated by single players (CCK). The effective factors in choosing MNP service by consumers have key role in the success of the service provision [2]. Some of these impressive factors are: number porting costs, the required period for porting number and competitive environment of the market that is affected by quantitative specifications such as the tariffs and also by quality of offered services

International experience of MNP has been limited and only partially successful [3]. According to Wikipedia online, MNP is operational in was introduced earlier in countries such as Netherlands, Hong Kong, UK, Switzerland, Australia and Singapore around ten years ago. In Africa, number portability has been implemented in South Africa (2006), Nigeria one year after and Egypt in 2008. Hong Kong's was the most successful with a high percentage of those changing networks porting their numbers, and with porting times of 1 - 2 days. While in the Netherlands and the UK demand was disappointing due to long porting times of up to 28 days, significant porting out charges, complex processes and some regulatory gaps [3].

There are four mobile service providers in Kenya namely: Safaricom, Airtel Kenya, Yu and Orange with market shares of $76 \%, 13 \%, 6 \%$ and $4 \%$ respectively as at June 2011 (CCK) [4] of the 20 Million customers' base.

There were issues identified by the Communication Commission of Kenya (CCK) that needed to be addressed by the MNP provider such as: technical solutions, service provision procedures, dispute resolution mechanism and implementation time frame. The technical issues to be addressed is so as to make the transition as smooth as possible, service provision procedures is so as to make each participant responsible for their actions and support the service implementation, dispute resolution is so as to make conflict resolution procedure as fast as possible and time frames to give deadlines to both parties on their obligations as explained by the Communications Commission of Kenya.
Whenever a technology is implemented, it becomes necessary for it to be measured and evaluated either on its success or failure. This paper examines the success or failure of MNP technology in Kenya. The study sought so as to compare the technology's performance in Kenya as compared to that of other countries which launched the service earlier. This was done primarily by first looking at the statistics in other countries and comparing the same to the Kenyan scenario.

\section{Trends}

There are some selected countries that have been reviewed in order to give a benchmark. The three countries described are Finland, Sweden and Hong Kong. The graph below shows how each country performed after launching the service.

There is an observation therefore from Figure 1 below that in Hong Kong, the technology had the highest embrace between $1.6 \%$ and $4.3 \%$ in which as the technology came of age, it was seen as decreasing in use. In Finland, there was the highest swing of between $0.8 \%$ and $4.3 \%$ within 15 months. There was very minimum effect of the technology in Sweden which means there is a very high degree of customer loyalty to their service providers as explained by Smura [5].

It is necessary to consider other African countries since they fall in the same category as the subject of study here and how this technology was adopted by customers. This is done on the following countries which have implemented the technology as shown in Table $\mathbf{1}$ as follows.

According to the daily news Egypt published in 2008 [6], two months after introduction of mobile number portability service, the number of subscribers who switched service providers constituted 0.02 percent of total mobile subscriber base.

MNP was endorsed in late 2005. Operators took a long time (over 9 months) to given their subscribers the option of switching [7]. In countries where MNP it exists did

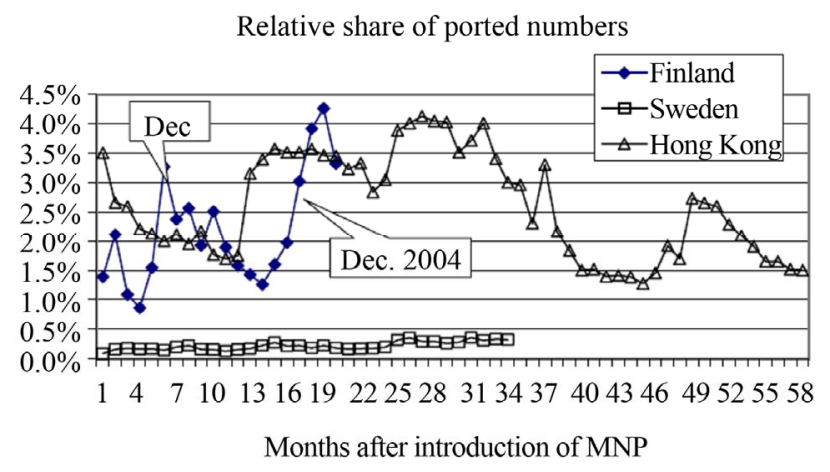

Figure 1. Ported numbers in relation to post-paid subscriptions in three European countries Source (Fierce price competition and teaching to port numbers-investment in future generation subscriber base). 
Table 1. MNP implementation in some countries.

\begin{tabular}{ll}
\hline Year & \multicolumn{1}{c}{ Country } \\
\hline 1997 & Singapore \\
1999 & Hong Kong, UK, The Netherlands \\
2000 & Switzerland, Spain \\
2001 & Denmark, Sweden, Norway, Portugal, Australia, Cyprus \\
2002 & Italy, Belgium, Germany \\
2003 & Finland, France, Iceland, Greece, Ireland, Luxembourg \\
2004 & Slovakia, South Korea, Austria, USA, Hungary \\
2005 & Taiwan \\
2006 & Czech Republic, Croatia, Saudi Arabia, Oman, South Africa \\
2007 & Canada, Pakistan, Israel, Nigeria \\
2008 & Brazil, Malaysia, Mexico, Bulgaria, Egypt \\
2009 & Ecuador \\
2010 & Peru, Thailand, Jordan, Kuwait, Albania \\
2011 & India \\
\hline
\end{tabular}

Source: Wikipedia online.

not imply any radical increase in switching activities. But it provided an alternative that ensures that operators treat their customers better [8]. It had to be right so that it does not experience a down-fall.

MNP implementation was a welcome idea for the customers but did not gather the required force; it was not widely accepted as a long-term solution for high call and interconnection rates but provide an avenue to control. MNP created an exciting competition among the mobile phone service providers with each determined to retain customers.

The parties involved in rolling out MNP in Kenya include: The mobile service providers: Safaricom, Airtel Kenya, Yu and Orange and their agents who have been contracted to carry out customer service on their behalf. The regulator: In Kenya the regulating body is the Communications Commission of Kenya (CCK). This is the body responsible for enhancing fair play and resolving conflicts. The MNP service provider: Mobile Porting Access Limited and the customers, who consume this product.

Before one considers porting, one need to register his/ her number the government of Kenya gave a directive that all mobile numbers be registered by some identification documents that are required to authorize porting just like any other country.

\section{Technological Implementation of MNP}

The basis of MNP technology implementation entails an extensive amount of effort and revision in the telecommunications infrastructure. The implementation includes a number portability database; the number portability database (NPDB) keeps track of the ported numbers, their respective service providers and a selection of an appropriate routing method for different types of calls and other value added services. The diagram (in Figure 2) [9] shows a summary as put by the Communications Commission of Kenya on MNP.

The procedure for postpaid customers is however different due to their business model, it has various detailed business rules including contracts signed with the provider, the authorizing person to take care of corporate and individual accounts, offers that accompanied the package during migration to post pay, needs to be taken care of by the policy.

The basic guideline to porting your number as provided by the regulator is that when porting, you need to change your subscriber Identity Module (SIM) card. Much as the process seems to be like acquiring a new connection, you retain your number. According to the CCK (2011) the general procedures in number portability are:

1) The Subscriber opens an Account with the new (Recipient) Operator and pays the Per-Port Charge (Ksh. 200 Approx. \$2.3). This is for them to be known by the recipient.

2) The subscriber installs a new SIM that has the number that they are already using with the old (Donor) Operator. To enable porting to be possible.

3) The subscriber requests the new operator to close their account with the old (donor) operator; to enable them start activate a new account at the recipient.

4) A request is made to all operators to change their routing arrangements so that calls can be routed directly to the new operator; this will enable the subscriber to continue with the service as usual.

5) The total turnaround time in the porting process is a maximum two (2) working days including all stages; this is the service level agreed time.

6) Any porting process beyond two porting days shall be recorded by the CRDB and shall also form part of the key performance indicators reporting. Which will be used as a measure of performance of the individuals working there as part of annual appraisal.

If a customer is dissatisfied by the service, there is an option given called cooling off.

It is a 14-day time after porting in which you are permitted to go back to your donor operator. You will not be charged early termination fees if you exercise this option.

\section{Findings}

The Communication Commission of Kenya (CCK) had anticipated that the service will have a high demand but the reception has been rather low such that after a week 


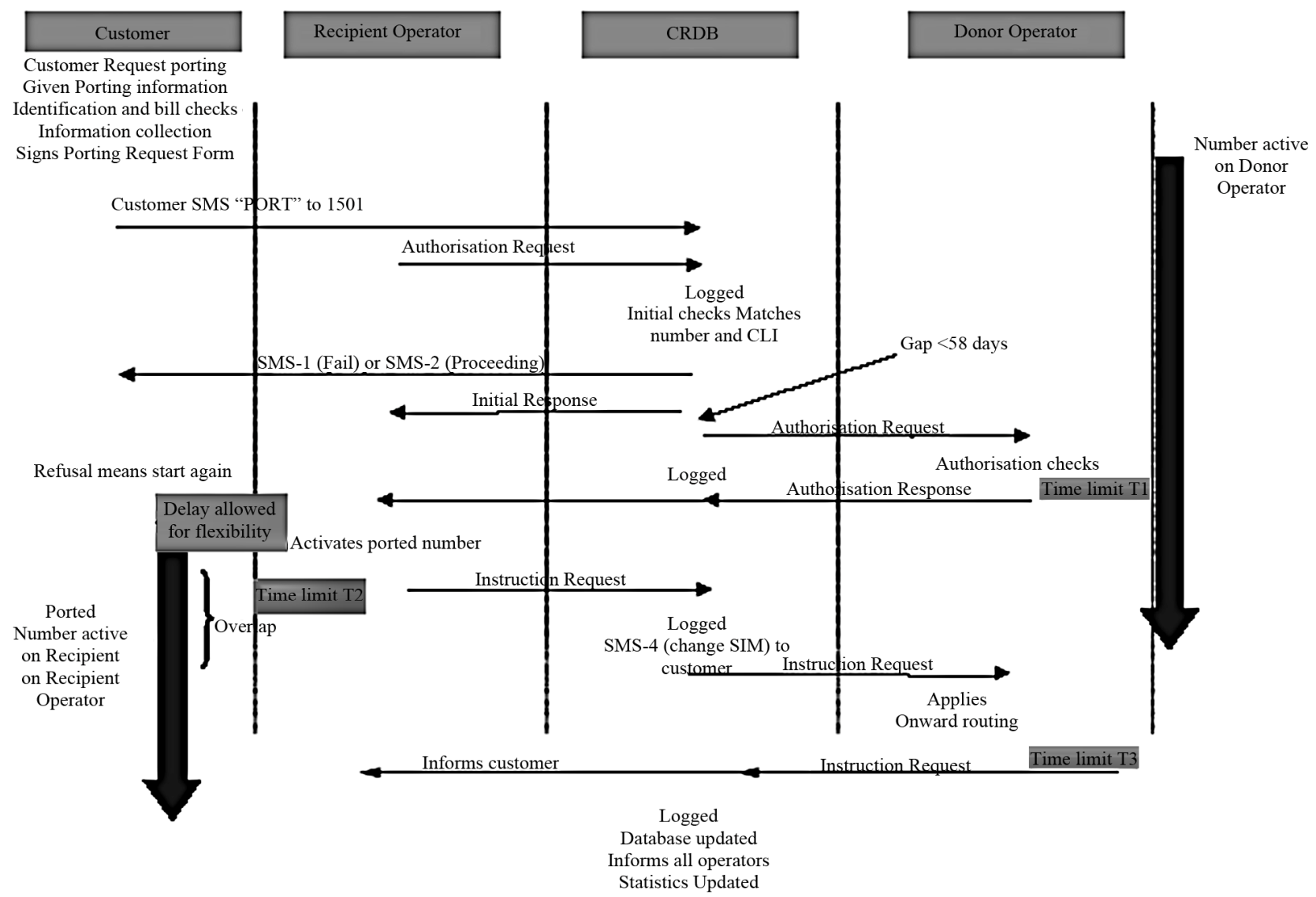

Figure 2. Source CCK guidelines on porting (2011).

about only 300 people had ported to different networks out of the 20 Million customer base. This is a very insignificant number considering the infrastructure investment and advertisements which had been run in the print and electronic media. This means that the service was not well accepted by customers as a solution to issues they may be having with their service providers.

MNP has forced carriers to work harder to retain customers by improving customer service as seen in the aggressiveness of some providers doing a door-to-door campaign for customers to port to their networks. This means there is more than marketing that may make customers to port and that other issues affect the choice to port. This is mainly due to the added value services received in various service providers.

Teething problems between carriers caused unacceptable porting delays of days which led to exchange of harsh complaints and counter-arguments from two major operators where one accused the other for sabotage, and the replies through the media equally harsh that one provider was not giving the whole and right information to customers. There have been cases in courts where customers accuse some providers of delays in porting hence loss of business [10]. To solve these issues carriers have had to make considerable evolution to their in-house op- erations and procedures to avoid confrontations with customers, the competitors and the regulator either through the media or in their boardrooms.

MNP can be seen from the improved customer retention strategies introduced by the service providers through special pricing deals, reward service offers such as points reward scheme adopted by a major market shareholder which has had various offers coming with it, bundling of services and other promotions.

\section{Recommendations}

An observation made on carriers who do not have a large network of agents need to broaden their base so as to reach the customers especially in rural area centers. Service providers must invest in tools that empower customers and customer care agents to reduce the amount of time they spend resolving a customer issue without compromising the quality of the interaction explained by $\mathrm{O}$. John [3]. One solution lies in filtering calls by directing them to an automated interactive voice register to handle frequently asked questions or provide a web self-service function.

For forecasting the network needs as part of providing porting is having the available capacity to deliver and 
receive the traffic that flows between the interconnecting networks. To do so, a planning process must be followed between the interconnecting operators so that investment for additional capacity can be agreed, budgeted, and installed in time to meet the forecasted demand [3].

Each carrier needs to identify their particular problems and remedy each through software patches, improved systems, well trained shop-front staff and enhanced customer education with other carriers and customers as explained [2]. According to a press release by one of the service provider (2011) [11], there was concern that customers are not given the right information. Customer care agents need to deliver superior customer service experiences as they help customers from answering their questions about MNP to providing number porting and related technical support and knowledge management [12]. Service providers must invest in training their agents in rural areas to carry out the porting requests on their behalf.

Procedures to resolve differences over forecasts must be defined as well as what constitutes a bona fide request for additional interconnection capacity [13]. At a minimum, a mutual obligation to notify the other party of network changes and upgrades well in advance is needed to avoid disadvantaging one competitor over another.

With average revenue per user declining, quality of service and customer experience play a decisive role in a subscriber's choice of an operator. Mobile carriers need to adopt a multi-pronged strategy that focuses on the overall user experience so as to avoid losing customers to competitors.

The greatest beneficiaries receiving customers should develop the capability to handle a potential surge of inbound phone calls, respond substantively and accurately to inquiries, making offers in a way that persuades highvalue customers to continue to stay and engaging successfully with prospective subscribers.

The regulator should negotiate the movement of the money transfer service among service providers to be just like any other value added service such as SMS now that it is an SMS-based service.

There have been cases of migration delay as reported by the media, though a clear format of dispute resolution has been put in place by the regulator, there have been cases in the courts and it takes long to be resolved if left to the courts. The regulator should take up and resolve the cases instead. The regulator should facilitate the introduction of industry-wide regulatory changes to reflect changing technologies and sector conditions to enable fast resolutions of conflicts.

The regulator also should consider supporting more research on how best to implement MNP and other new Information Communications Technologies in a very dynamic environment of the mobile service sector in terms of technical solutions, policy and implementation.
The MNP provider should try to reach a near-real-time porting solution by establishing a complex solution between carriers to manage the messaging between the losing mobile carrier, the gaining mobile carrier, carriage service providers and other parties that need to route calls to the ported customer [14]. The provider should try to provide an integrated money transfer framework such that irrespective of the customer's network, he/she should be able to send or receive money provided it is in the same currency.

The provider should also consider investing in further research on how best to sell the MNP technology to customers and reduce barriers to the access of this service and develop an online porting platform to allow for a wider access to the customers who may be limited by time and location.

The provider may also consider assisting in developing a transparent banking solution via the various money transfer services such as M-PESA (A mobile money transfer service) on the M-KESHO (a platform in equity bank) and I\&M Visa Card platforms.

To mitigate effects of casual decision, based on incomplete information and done by the roadside at the instigation of commission-hungry agents, the customers must first confirm that they are well informed on customer procedures involved in MNP before making a decision to port and know the reasons and the time frame the porting process could be blocked before the service is resumed to avoid inconvenience. One should also understand how value added service such as Short message services(SMS), Voice Mail and Money transfer services would be handled when a number is ported; and understand how limited the disruption would be during the actual changeover.

\section{Conclusions}

MNP has brought a unique challenge for mobile operators and intensified the competition for retaining subscribers. Much utilization of the service was expected by the regulator, it did not meet its expectation hence there has been a miss of the technology in the market. The statistics as for the first three months are approximately 143,000 requests made out of the 20 Million customers, which makes $0.715 \%$ which is insignificant.

This implies a great maintenance of the status quo and this option acts as a regulation to other service providers who don't act in an anti-competitive behavior.

Considering the investments done where one service provider invested Ksh. 10 million (Approximately \$116 280) as released by Safaricom [12] which means if each of the four operators invested approximately the same amount using the 2010 (which has been dropping) average rate of spending per user (ARPU) of Ksh 437 (\$5) annually, it would take over 8 months to recover the in- 
vestment from the same customers excluding any operational costs.

This low response on the service also means that either, there is a high degree of customer loyalty among the subscriber base to their service providers [15] or there is an uninformed population especially among the people living in rural areas on the number portability.

In the end, MNP has been good to the customer in that it has made service providers more responsive in protecting their customer territories and locking out competitors. The service providers have been forced to seek the right customer experience that will help them build profitable, lasting relationships and differentiate themselves in an increasingly competitive market.

\section{REFERENCES}

[1] T. Durukan, I. B. Taylan and T. Dogan, "Mobile Number Portability in Turkey: An Empirical Analysis of Consumer Switching Behavior," European Journal of Social Sciences, Vol. 20, No. 4, 2011.

[2] H. G. Shakouri, "Impact on Dynamic Behavior of a TwoCompetitor Mobile Market: Stability versus Oscillations,” 2010.

[3] O. B. John, “Telcorum Case Study 2,” 2005.

[4] C. C. O. Kenya, "Statistics,” Nairobi, Kenya, 2010.

[5] T. Smura, "Mobile Number Portability: Case Finland," 2004.

[6] E. M. Sherine, "Vodafone Numbers Drop as Mobile
Subscribers Make the Switch,” Daily News Egypt, 2008.

[7] K. Naidoo, "Middle East \& Africa Market Perspective," Vol. 6, 2006.

[8] A. Oladejo, "Mobile Number Portability in Nigeria: A Note For the NCC," 2011.

[9] C. C. O. Kenya, "Procedures and Guidelines for the Provision of Mobile Number Portability Services in Kenya," 2011.

[10] Airtel, “10 reasons to HAMA to Airtel,” 2011. http://www.nikuhama.com/what-is-mobile-number-porta bility.aspx

[11] C. C. O. Kenya, "Public Consultation Document on Introduction of Number Portability in Kenya,” Nairobi, 2010.

[12] Safaricom, "Press Release,” Safaricom Limited, Nairobi, 2011.

[13] C. K. N. Bashar, J. Hamza, N. K. Noordin, M. F. A. Rasid and A. Ismail, "The Seamless Vertical Handover between (Universal Mobile Telecommunications System) UMTS and (Wireless Local Area Network) WLAN by Using Hybrid Scheme of Bi-mSCTP in Mobile IP,” 2010.

[14] S. A. Odunaike, "The Impact of Mobile Number Portability on TUT Students On-Line Connectivity," Presented at the Information Systems Educators Conference, Nashville, 2010.

[15] A. Caruana, "The Impact of Switching Costs on Customer Loyalty: A Study among Corporate Customers of Mobile Telephony," Journal of Targeting, Measurement, and Analysis for Marketing, Vol. 12, 2004. 